\title{
Crime on Bus Routes: an Evaluation of a Safer Travel Initiative
}

\section{Andrew D Newton ${ }^{1}$, Shane D Johnson ${ }^{2}$ and Kate J Bowers ${ }^{2}$}

Key Words: GIS, Bus Route Crime, Prevention, Evaluation, Analysis.

${ }^{\mathbf{1} E n v i r o n m e n t a l ~ C r i m i n o l o g y ~ R e s e a r c h ~ U n i t ~}$

Department of Civic Design

University of Liverpool

Liverpool

England

L69 3BX

Email: adnewton@ liverpool.ac.uk

Tel: (+44) 1517943116
${ }^{2}$ Jill Dando Institute of Crime Science University College London Third Floor, 1 Old Street

London

EC1V 9HL 


\section{$\underline{\text { ABSTRACT }}$}

This paper reports the main findings of an evaluation of an intensive four-week policing operation along a single bus corridor, aimed at reducing the extent of crime along the bus route. The evaluation, which adopts a mixture of quantitative evaluation techniques, demonstrates that the operation was successful both in increasing officer arrest rates (up to four times for the officers who worked on the scheme), and also in reducing crime levels for particular crime types, namely assault and theft from vehicle, up to 400 metres from the route. A conceptual discussion is provided as to how to measure the effectiveness of an operation with no geographically predefined action area and to define the relationship between action areas and displacement or diffusion zones. Consequently, this evaluation examines both the influence of the scheme within a predefined distance from the route, and also proposes a method for determining the likely range of influence of the scheme in terms of physical distance. 


\section{$\underline{\text { INTRODUCTION }}$}

A substantial body of research has contributed to understanding of what works in crime prevention (for reviews see, Sherman, Gottfredson, MacKenzie, Eck, Reuter and Bushway, 1998; Visher and Weisburd, 1998). However, there is a paucity of research concerned with 'what works' in reducing crime along public transport corridors (local transit service routes). Consequently, this article presents the main findings of an evaluation of a police operation that aimed to reduce crime and disorder along a single bus corridor.

To provide a context for the forthcoming analyses, we begin by considering the significance of crime and disorder on bus routes, and examine the potential measures available for their reduction. We then discuss the need for evaluations of these kinds of preventative measures both to determine the relative successes and or failures of the schemes, and to inform future measures and disseminate best practice.

\section{$\underline{\text { An Overview of Crime and Disorder on Public Transport (Public Transit) }}$}

Fear of crime on public transport is a possible limiting factor to public transport usage, and in the UK the then DETR (1998) suggested passenger levels could be increased by $3 \%$ at peak and $10 \%$ at off peak times if such fears were addressed.

In order to reduce fear of crime along public transport corridors, it is necessary to tackle the actual level of crime and disorder, indeed 'the ultimate goal should be to make riders feel safe by ensuring that they are safe' (Nelson, 1997). However it is difficult to gauge the level and extent of crime and disorder that occurs on public transport for a 
number of reasons, primarily because public transport agencies do not collect information on such incidents in a systematic or standardised format (Esteal and Wilson, 1991). In the United Kingdom, this problem is compounded on buses because the police do not record crime incidents on the bus as a specific category of crime incident, there is no dedicated transit police force, and bus operators outside of London have no statutory requirement to report incidents (DTLR, 2002). Furthermore, it is problematic to give a meaningful static location for a crime committed on a moving bus. Hence, it is extremely difficult to determine the amount of crime that physically occurs on public transport from police recorded incidents. However it is possible to determine the amount of crime that occurs along an individual bus corridor, rather than on the bus itself, using police recorded incidents, as will be demonstrated later. This is important when considering the holistic approach to the public transport journey (DETR, 1999) whereby safety on the public transport journey should be seen in the context of the whole journey. This incorporates not only travelling on the bus, but also waiting at stops and walking to, from or between stops.

In addition to this, the extent of under-reporting of incidents of bus crime is also unknown. Findings from a survey conducted by Levine, Wachs and Shirazi (1986) in Los Angeles suggest that there are 25-30 times more bus crime incidents than are reported. In England and Wales, the British Crime Survey (BCS) is often used to estimate the amount of under-reporting of crime. In an analysis of the BCS, Mirlees-Black, Budd, Partridge and Mayhew (1998) found that only $44 \%$ of crime incidents were reported to the police and this varied by crime type (57\% robbery, $43 \%$ thefts from vehicle, $26 \%$ incidents of vandalism). It is unclear how this figure relates to bus crime because the survey does not support a breakdown by mode of transport (by bus or by train for example). 
It is also suggested (DTLR, 2002) that there is a significant difference between the perceived, and actual levels of crime and disorder on public transport. An alternative measure of the extent of crime on buses may be derived through surveys of passengers. To illustrate such findings, a recent UK survey of bus passengers found the following: $16 \%$ of passengers experienced and 29\% observed verbal abuse, 28\% experienced and 20\% observed objects thrown at a bus, $2 \%$ experienced and $6 \%$ observed assault, and, $3 \%$ experienced and 3\% observed theft/muggings (Baker and Bewick, 2001).

It is obviously difficult to tackle problems of crime and disorder along bus routes (and consequently to reassure the public about the safety of using buses) when the extent of crime either on the buses or along bus routes is not fully known.

\section{$\underline{\text { Crime Prevention Measures }}$}

In relation to crime prevention in general, according to routine activities theory (Cohen and Felson, 1979), for crimes to occur the following must converge in space and time: a motivated offender, the absence of capable guardians against crime and the opportunity to commit crime. Capable guardians are not restricted to police officers or security guards but include anyone whose presence or proximity discourages a crime from happening and may include ticket inspectors and others who, by just being present at a given place and time serve as guardians against crime.

Opportunities for crime vary over time and space, as does the presence of offenders. Consequently, different solutions may be required in different areas and environments. Nevertheless, policies aimed at preventing and reducing crime generally do so by exerting influence over one or more of the three routine activity theory elements. For example, one 
approach to affect change would be to improve surveillance and by helping to ensure that sufficient 'guardians' are present at specific times of the day to make it more difficult for a motivated offender to target a suitable victim, perpetrate a crime (e.g. robbery, theft, assault) and make an escape. Similarly CCTV schemes, and in particular those that initiate some form of law enforcement response (where appropriate) may increase guardianship. A further approach is to reduce the vulnerability of potential victims, and hence opportunities for crime, by protecting them from motivated offenders. For instance, a number of studies have demonstrated that so called 'target hardening' schemes, which involve the installation of new door/window locks and other physical security measures, are effective in reducing the risk of burglary (e.g. Anderson, Chenery and Pease, 1995; Johnson, Bowers, Young and Hirschfield, 2001; Bowers, Johnson and Hirschfield, 2003).

A diverse range of potential preventative measures that could be implemented to tackle crime and disorder on public transport systems exist. Examples include improving visibility or lighting, increasing staff presence, allowing police in uniform to travel on buses for free, the use of CCTV, emergency help points, cleaning and regular maintenance, and the use of Transport Wardens. Useful overviews and examples of such schemes are reported in detail elsewhere (e.g Atkins, 1990; Felson, Belanger, and Bichler, 1996; Eck, 1997; Needle and Cobb,1997; Smith and Clarke, 2000; DTLR, 2002). One finding that has emerged is that the most successful schemes tend to be those which are multi-agency and that adopt multi-tactical approaches.

However, perhaps the biggest limitation of many previous schemes aimed at reducing crime on public transport is that interventions have been applied on an ad hoc basis or as a response to funding opportunities, rather than as a result of the precise a-priori matching of a specific solution to a specific problem. As Easteal and Wilson (1991, p12) 
observe 'the first task of any crime prevention measure must be to analyse existing data to establish incidence patterns including type of crime, location, time and other relevant environmental factors', and that transit agencies 'often fail to conduct victimisation or pattern analysis studies to determine the exact scope of their problems before they implement remedial measures'. This in part may be explained by the difficulties involved in measuring the extent of bus crime as previously highlighted.

Importantly, knowledge about the successes and failures of schemes implemented is limited due to a lack of, or difficulties in, evaluation of the measures taken. Nevertheless, some evaluations have been conducted (Van Andel, 1989; Laycock and Webb, 1992; Carr and Spring, 1993; Poyner, 1993; Felson et al., 1996; and La Vigne,1997). Although these evaluations demonstrate successes achieved in crime prevention on public transport, there are inherent methodological difficulties in determining the effectiveness of these measures (Eck, 1997). On a transport system there are a number of inter-connected settings that make it difficult to identify appropriate comparison areas, and there also are a variety of potential victims (staff, passengers and facilities). More generally, it is evident that there is a paucity of evaluation research concerned with interventions aimed at reducing crime and disorder on public transport systems (Sherman et al., 1998). Thus, there is a clear need for appropriate and robust evaluations of this type of scheme.

In the current paper we will adapt a number of quantitative evaluation techniques that have been used more generally in the field of crime prevention. In particular, Sherman et al., (1998) have recently emphasised the need to use robust evaluation designs that, as a minimum, consider changes in an action area relative to a suitable comparison or reference area. Evaluations that consider changes in an action area over time alone fail to account for what would have happened in the absence of a particular scheme, commonly referred to 
as the counterfactual. Thus, for each of the analyses presented here it was important to identify an appropriate comparison or reference area (or group), a task that was aided by the use of a geographical information system (GIS).

\section{Operation Bream: A Safer Travel Initiative}

Operation Bream was a high visibility intensive policing operation that took place along a single bus corridor on Merseyside for a four-week period from the $22^{\text {nd }}$ April 2002 to the $19^{\text {th }}$ May 2002. This multi-agency operation involved the targeting of criminals both on and around one bus route by a dedicated police team in conjunction with a boosted revenue protection operation implemented by Revenue Protection Officers. Police officers from the Operational Support Unit were utilised and worked on their rest days to ensure that the operation did not prevent officers from performing their regular duties, and hence did not hinder police resources. Additional support was provided by traffic wardens, MASS security officers (a dedicated local rapid response security firm for public transport) and high-tech on-bus CCTV. The operation was implemented on a single bus corridor that, it was suggested, experienced a relatively high amount of crime compared to other bus routes. This is subsequently referred to as the action route and is shown in figure 1.

This bus route traverses through two of the five districts of Merseyside, Liverpool and Sefton. The 2001 Census of Population reveals Liverpool's population in 2001 was approximately 440,00 and Sefton 280,000. The Census also reveals that in Liverpool 48.3\% of houses are without a car or van and in Sefton this figure is $31 \%$ (compared to national average for England of 27\%), highlighting the importance of bus use in the area. The route 
also traverses through a mixture of land use types, from Liverpool City Centre, through Bootle Town Centre, to the more rural-urban fringe area of Thornton.

Take in Figure 1 Please

Importantly, the operation itself attempted to reduce crime not only on buses, but also along the actual bus corridor itself. Therefore the bus route was selected as the unit of analysis for this evaluation.

During the police operation, officers accompanied revenue protection inspectors on buses. Back-up teams of six police officers also provided support in a police vehicle. The officers used the bus as a means to patrol the bus corridor as opposed to doing it on foot or in a police car. It is suggested that this is a fairly unique method of policing the route and one that criminals would not expect. Therefore along the bus route there was a mixture of policing including that done in vehicles, on foot, and 'on bus' patrols. Any previous police presence on the bus route (pre-scheme) was a result of routine police activity that happened to occur along that bus route. Such activity was not intended to tackle crime specifically along the route, but was rather a response to calls for service in the area.

At this point, it is also important to discuss the action area for this police operation; the area where it is intended to reduce crime. Unlike many crime reduction initiatives, such as those aimed at preventing burglary which generally have a defined geographical target area, it is difficult to precisely define the target area that this operation was designed to impact upon. For example, one could examine changes along the action route itself, all crime within a certain distance of the action route, or all crime visible to police officers patrolling the route. This raises the conceptual issue of whether the effect of the scheme 
should be measured in terms of a reduction in a specific target area, or whether it would be more appropriate to test the distance over which the scheme might feasibly have an impact. This issue is not easily answered and thus we take a combined approach here.

Anecdotal evidence from a similar scheme implemented in London, Operation Seneca, suggested that for this operation reductions in crime were realised up to distance of $200 \mathrm{~m}$ from the bus route. Thus, as a starting point, we examined changes within $200 \mathrm{~m}$ of the bus route. Additionally we considered changes across greater distances of up to $500 \mathrm{~m}$ away. As the majority of police resources dedicated to Operation Bream were concentrated along the route itself, it seemed less plausible that changes observed at distances greater than this could be reasonably attributed to the scheme.

The aim of the initiative was essentially to 'pilot' an approach to tackle crime and disorder along the bus route. When undertaking an evaluation of an operation it is important to examine both what the intended outcomes are, and the processes by which they would, in all likelihood, be expected to be achieved (Weiss, 1998). As a result, it is important not only to ask if the operation worked, but what made it work (or fail). For the current initiative, there exist a number of potential mechanisms that might affect a reduction in crime along the bus route, including the following:

- Intensive policing along the bus route may result in people noticing extra policing, which in turn may impact upon offenders' behaviour, since they may avoid this route.

- Increased police presence may lead to the police observing more crime events. A subsequent associated increase in arrest rates may consequently deter other potential offenders from committing offences along or around the bus route. 
- Another possibility is that the increased police presence along bus routes may result in bus drivers becoming more vigilant, and informing the police more regularly and rapidly of incidents. Given the limited window for intervention associated with most crimes, this may enable the police to respond to and prevent or detect more (serious) incidents.

The expected outcome of each of these possibilities, of course, would be a reduction in crime and disorder along the bus route. Part of the research conducted was to identify the most salient objectives of the scheme and to determine how effective the initiative was in relation to each of these.

The primary objective of the scheme was to increase the number of capable guardians within the target area. In addition to the high visibility policing along the route, officers were also accompanied by Revenue Protection Officers to assist them in their duties, thereby increasing guardianship still further. Theoretically, this should reduce the likelihood of offenders committing crimes within the area, and increase the probability that active offenders operating within the area would be apprehended.

Previous research has demonstrated that the positive effects of police crackdowns may continue after the termination of the operation, an effect that Sherman (1990) refers to as residual deterrence. Thus, a second aim of the initiative was to see if there was evidence of this phenomenon where reductions were observed.

A third objective of the operation was to see if, as an indirect result of the activity, there was a reduction in crime in other areas in the near vicinity of the action route, a socalled diffusion of benefit (Miethe, 1991). This is said to have occurred when the positive 
effects of a scheme extend beyond its operational boundary. For instance, where offenders are deterred from committing crimes both within an action area and immediately adjacent areas. However it is equally possible that the operation may negatively affect patterns of offending in areas adjacent to the action route, for instance, where offending behaviour is simply displaced to neighbouring areas (e.g. Bowers and Johnson, 2003), or offenders deterred from committing one type of crime simply commit other (replacement) crimes. Thus, if there was a reduction in crime, the scheme may also cause geographical displacement, crime-switch displacement, or a more desirable outcome such as a diffusion of benefit.

As discussed above, in terms of this operation, for which there was no precise action area, an important issue is whether it is appropriate to measure possible displacement/diffusion of benefit over space, or whether any changes in the spatial distribution of crime should be conceptualised in terms of an action area effect. Thus, should the impact of the operation be considered in terms of a 'range of effect' rather than in the more traditional way of considering changes in both the action and surrounding areas. The main rationale for examining patterns in the surrounding area(s) in other evaluations is to determine whether the effects of the scheme extend beyond the operational boundary. In initiatives such as that evaluated here the operational boundary is less clear as the precise area over which the police patrolled may well have extended beyond the boundary of the bus route, depending upon circumstances. Thus, in the absence of detailed data on the area covered it seems less reasonable to think in terms of a distinct target area and displacement zone. 
From the above discussion, a number of specific hypotheses were generated regarding the potential impacts of the scheme. In particular, as part of the evaluation we tested the extent to which, as a result of the intervention there was:

1) An increase in arrest rates for officers working on Operation Bream

2) A reduction in calls for police service along the action route

3) A decrease in recorded crime within and around the bus route

4) Evidence of a residual deterrence effect

In the sections that follow we discuss the methods used to explore each hypothesis and present the results of the consequent analyses.

\section{METHODS AND RESULTS}

\section{Changes in Arrests Rates}

Different policing operations are likely to have varying effects on police arrests, but the general aim is to increase the number made. It was not possible to examine the number of successful prosecutions realised as a direct result of Operation Bream because of the time required to process offenders through the Criminal Justice System. However, since there was no reason to suspect that arrests made as a result of the operation were less (or more) likely to lead to successful prosecutions than other operations, the examination of arrest rates was used as the critical measure of success here.

The effect of the initiative on officer arrest rates could be assessed in a number of ways. For instance, it is possible to compare officer's arrest rates during the period they 
worked on the initiative with either their arrest rates at an earlier time, or, with other officer's arrest rates during the period the initiative took place. Here we use a combination of these two approaches. This ensures two things. First, that the analyses controlled for the individual differences that exist between police officers that may affect performance, such as levels of experience, motivation and other psychological factors. Thus, by using the same officers and comparing their performance at different time periods we could be relatively certain that any changes in arrest rates could be attributed to the initiative rather than individual differences. Second, by comparing the change in arrest rates for those who participated in the operation with those who did not, it was possible to control for potential seasonal patterns in arrest rates.

The 85 officers who worked on the operation were identified and their arrest rates calculated for the periods prior to and during implementation. Arrest data for one complete month, March 2002, were utilised for the before period ${ }^{1}$ to ensure comparability with the (one month) implementation period. Arrest rates were calculated by dividing the number of arrests made by each officer by the number of days worked. For the period of implementation, the number of days worked on the operation and the associated arrests made by each officer were known. Unfortunately, for the historic period, data on the number of days each officer worked were unavailable, and hence estimates were derived for the number of days each officer worked, based on typical shift patterns. To increase the sensitivity of the analysis high (assuming officers worked 15 days per month), medium (20 days) and low (25 days) estimates of the arrest rates were produced. Constructing the estimates in this way meant that a range of baseline arrest rates were generated.

\footnotetext{
${ }^{1}$ Data on arrests were only available for complete calendar months
} 
Table I shows that the average baseline arrest rates ranged from 0.09 to 0.15 arrests per day. This means that for the baseline period, on average, officers who worked on the operation made one arrest roughly once every 7 to 10 days. It is clear from the results shown in Table 1 that the operation had a positive effect on the average officer arrest rate. In fact, the average arrest rate during the operation was roughly three to four times higher than that for the baseline period. Expressed in a slightly different way, whilst working on Operation Bream, officers made arrests almost every other day (compared to approximately once a week for the baseline period). A series of related-samples t-tests confirmed that the differences in arrest rates were statistically significant for comparisons that considered the high $(\mathrm{t}(84)=5.0, \mathrm{p}<.00001$, two-tailed $)$, medium $(\mathrm{t}(84)=4.65, \mathrm{p}<.00001$, two-tailed $)$ and low estimates $(\mathrm{t}(84)=4.04, \mathrm{p}<.00001$, two-tailed) of the baseline arrest rate.

To examine the possibility that the results could have been due to a more general factor operating across the wider policing area, we also estimated the average arrest rates for Merseyside police officers that did not work on Operation Bream. The results of this analysis, shown in Table 1, suggest that there was no change in the average arrest rate across Merseyside ${ }^{2}$. This demonstrates that the increase in arrest rates observed for officers who worked on Operation Bream was not simply commensurate with the general trend observed elsewhere. This finding is important as it helps to rule out rival explanations of the pattern observed. For instance, it is unlikely that the increase in arrest rates could be explained in terms of a seasonal pattern or a general change in policing policy.

To express the findings in a slightly different way, a total of 90 arrests were made during Operation Bream. Since officer arrest rates were around 3-5 times higher during the

\footnotetext{
${ }^{2}$ This was derived by dividing the total number of arrests made during the relevant periods by an estimate of the number of officers who could potentially make arrests during this period.
} 
operation, using a simple calculation, it is possible to conclude that had the officers who worked on the operation worked the same number of days in their usual way, they would have made between 15 and 30 arrests. Thus, the officers who worked on the initiative made up to 75 additional arrests than they would have done had they completed their normal duties.

There are two potential interpretations of the increased arrest rate of officers. The rise in the volume of arrests indicates that there was definite evidence of a police crackdown in operation. Seen in this light, the increased arrest rate can be viewed as an indicator of effective implementation of the scheme. However, the increase in the actual rate of the arrests also suggests a positive impact of the scheme, since there is no reason to suggest that officers who made arrests on the scheme would not have had the opportunity to have made arrests during their normal duties. In these terms therefore, the increase in the arrest rate is a positive outcome of the scheme. However, it is not a final outcome in terms of actual crime reduction. Rather, an increase in the arrest rate should reduce the number of offenders available to commit crime; or demonstrate heightened risks of being caught to other offenders. In this sense, therefore, the arrest rate can be seen as an "intermediate outcome" (see also Weiss, 1998), as it leads to a chain of events that should affect the final outcome (a reduction in crime).

Take in Table I please 


\section{$\underline{\text { Calls For Police Service }}$}

Police calls for service records are a good indicator of public demand for police intervention, and have previously been used as a measure of 'formal social control' (Bowers and Hirschfield, 1999). To examine the effect of the initiative on calls for service, data were collected for the whole of Merseyside for the period 1 April 2001 to 31 July 2002, thereby providing data which covered the 12 months that preceded the scheme, the one month period during which the initiative was operational and the subsequent two months. Data for the after period were limited to a period of two months because further police operations were implemented along other bus routes in the reference area after this period.

The geographical location of the action route, digitised using a GIS, is shown in Figure 1. As the bus route was essentially a line on the map, a buffer zone, which surrounded the action route, was generated to define the likely area over which the initiative would have the most impact, and for reasons previously discussed a 200m buffer zone was constructed. For this analysis, because Command and Control records are only accurate to a resolution of $100 \mathrm{~m}$ the buffer zone was made up of all $100 \mathrm{~m}$ grid squares which intersected the area within 100 metres of the action routes. This produced a buffer zone which captured calls for service which occurred up to $200 \mathrm{~m}$ from the action route. The use of a larger buffer zone would increase the likelihood that any effects generated would have been diluted or 'washed out' (across a wider area), and hence not detected. Conversely, the use of a buffer zone that was too small would increase the likelihood of type I statistical error (rejecting the null hypothesis when it is in fact true) because any 
patterns observed would simply be unreliable (for a further discussion of these issues, see, for example, Bowers and Johnson, 2003; Hamilton-Smith, 2002).

To examine the effectiveness of the scheme, comparisons were made between the action route and a reference area, in this case the remainder of Merseyside, for the periods before, during and after the implementation of the initiative. The number of calls for all types of incident for the action route and the remainder of Merseyside, were standardised as a rate per 1000 households. As an indicative measure, for the 12 months prior to Operation Bream, the rates for all Command and Control calls were 2420 and 1130 for the action route and the remainder of Merseyside respectively. This indicates that demand for police services per household was over twice as high along the action route than for the remainder of Merseyside. A simple analysis of the number calls made for the before, during, and after periods of the operation (figure 2), demonstrates that for the reference area, there was a slight increase in the number of calls made during the before and intervention periods. In contrast along the action route there was a $22 \%$ reduction in calls for the same period. For the subsequent period (i.e. during - after) there were similar downward trends in the number of calls for both the action route and reference area.

Thus, the pattern of results observed was clearly selective thereby suggesting that the reduction observed along the action route during the period of implementation could not be explained in relation to a more general trend, but was attributable to the scheme.

Take in Figure 2 Please

However, the above results do not indicate whether the change observed along the action route was statistically reliable or the result of a chance fluctuation. Thus, it was 
necessary to derive a standardized measure of effect size. To do this we used an approach advocated by Farrington and Welsh (2002) which involves computing odds ratios. This approach is particularly useful where the data available is limited to levels of crime before and after the inception of a scheme for both action and reference areas, as was the case here.

An important reason for using odds ratios is that they allow the calculation of the statistical significance of the effect size observed. This is done by computing the standard error of the odds ratio (see Lipsey and Wilson, 2001) and then calculating a z-score. The statistical significance of the resulting z-score is established by consulting existing tables generated for the $\mathrm{z}$ distribution (as a rough guide, a value of 1.96 or more is statistically significant at the $5 \%$ level).

Fortunately, interpretation of an odds ratio is intuitive as they simply indicate the proportional change in crime in an action area relative to that in a comparison area. Thus, an odds ratio of 1.0 indicates a scenario where changes in calls for service in two areas are simply commensurate. An odds ratio of greater than 1 reflects a desirable outcome, whereby relative to the change observed in the reference area, there was a reduction in the action area. In contrast, an odds ratio of less than 1 indicates an undesirable effect, with the increase in calls for service in the action area exceeding that in the reference area. The magnitude of change is also readily interpretable. For instance, an odds ratio of 1.50 represents a situation where there was a 50\% increase in the reference area relative to the action area (1.20 a 20\% increase, and so on). Expressed in a slightly different way, an odds ratio of 1.50 represents a situation where there was a reduction of $33 \%(=1-1 / 1.5)$ in the action area relative to the reference area (1.20 a 17\% decrease, and so on). 
Figure 3 is a 'forest plot' which shows the odds ratio (and associated 95\% confidence limits) calculated for the change in calls for service in the action area relative to the remainder of Merseyside. A reference line shows the baseline odds ratio of 1 . As noted above, an odds ratio of 1 indicates that the change in the action area was simply in line with that observed in the comparison area. For odds ratios where the $95 \%$ confidence limits overlap the baseline odds ratio of 1 , the change in the action area was (statistically) nonsignificant. Where they do not, the change was statistically significant. Thus, it is apparent that, relative to the remainder of Merseyside, during the operation there was a significant reduction in police calls for service (odds ratio $=1.25, \underline{\mathrm{z}}=10.17, \mathrm{p}<.0001$, two-tailed).

However, it is unlikely that the increased police presence from the operation would impact on all types of calls for service. For example, certain types of offences such as domestic disputes occur mainly indoors, and other calls for service are administrative or orientated towards public assistance. Consequently, it is unlikely that the operation would affect these call types. Thus, in addition to examining 'all calls for service' a separate analysis was conducted for calls for service that were concerned with disorder alone, a type of call for service that police presence on the route should logically impact upon. The disorder category included serious disorder; incidents on licensed premises; minor disorder; drunkenness; disturbance involving juveniles; and disturbance on a public service vehicle. It was hypothesised that the operation would have a particular effect on these types of disorder, as police presence could plausibly discourage them. The results indicated a significant reduction in calls of this type (odds ratio $=1.13, \underline{z}=2.2, \underline{p}<.05$, two-tailed), thereby validating our prediction.

Considering the two-month period that followed the termination of the operation, relative to the period before, the odds ratio for all calls for service was $1.21(\underline{z}=10.15$, 
$\mathrm{p}<.0001$, two-tailed) suggesting that the overall effect of the scheme may have been sustained, at least for this period. In contrast, for disorder alone, the odds ratio was 0.97 $(\underline{\mathrm{z}}=-0.78, \underline{\mathrm{p}}=\underline{\mathrm{ns}}$, two-tailed), indicating that after the termination of the operation, the demand for police services relating to incidents of disorder returned to its pre-operation level. This suggests that during the operation there was a significant effect of the scheme, with their being a general reduction in the number of calls for police services. However, following the termination of the operation, there was some evidence of a sustained effect, but this was selective and calls for service regarding disorder resumed to their pre-operation levels.

\section{$\underline{\text { Recorded Crime }}$}

To see if the operation had an impact on recorded crime, disaggregate level data were obtained for the county of Merseyside for the types of crime which, theoretically, were most likely to be affected by the operation. These were burglary, criminal damage, theft from vehicle, theft of vehicle, assault, robbery, theft, and fraud. To allow us to examine both the effectiveness of the scheme during implementation, and to see if any effects extended beyond this period in the absence of further implementation, the data acquired covered the periods before, during, and after the implementation of the scheme. The data obtained included a grid reference accurate to within one-metre, and a date and time field. Consequently, using a GIS it was possible to produce maps which showed precisely when and where each crime occurred.

As with the analysis of calls for service, a 200m buffer zone which surrounded the action route was generated. In addition, further buffer zones were generated for the action 
route to allow us to examine the distance over which the scheme had an impact. Thus, two types of concentric buffer zones were produced for the action route. The first, which represented the action route was simply a $200 \mathrm{~m}$ buffer zone. The second type was a series of overlapping buffer zones that had the same morphology as the first but extended from it at intervals of $100 \mathrm{~m}$. For example, the first of these buffer zones extends between 100 and 300 metres away from the route; the second between 200 and 400 metres and so on (see figure 1).

To examine the effect of the operation on levels of recorded crime we used the odds ratio approach discussed above. In the first instance, we computed odds ratios for the central $(200 \mathrm{~m})$ action route. The rationale for doing so was that because the intervention was concentrated within this area it was reasonable to assume that should the scheme have any crime reductive effects they would be most apparent within this area. A number of patterns are evident from the results presented in figure 3. First, considering all recorded crime, relative to the remainder of Merseyside, there was a small reduction along the action route. However, this was not statistically significant $(\underline{\mathrm{z}}=1.03, \underline{\mathrm{p}}=\underline{\mathrm{ns}}$, two-tailed). Second, with the exception of the crimes theft from vehicle and burglary non-dwelling, reductions were observed for each type of crime. Third, whilst the reductions were fairly substantial for a number of crimes, the only changes that reached statistical significance were for the crimes of assault $(\underline{z}=2.22, \underline{p}<.05$, two-tailed $)$ and theft from vehicle $(\underline{z}=2.13, \underline{p}<.05$, twotailed). Thus, the operation appeared to have had an effect on recorded crime but this was limited to two types of crime. Importantly, the finding that the only changes that were statistically reliable were for the crimes for which there was evidence of a reduction suggests that there was no evidence of crime switch displacement. 
Take in Figure 3 Please

To examine whether or not there was evidence of residual deterrence, we also computed odds ratios for the period that followed the termination of the scheme. For this analysis, the levels of crime along the bus route (and the reference area) before and after (rather than during) were compared. For obvious reasons this analysis was restricted to those crimes for which there was evidence of a statistically significant reduction during the implementation of the scheme. For the crime assault, it was apparent that following the termination of the operation, the level of crime along the route resumed to its pre-operation level (odds ratio $=1.02, \underline{\mathrm{z}}=0.13, \underline{\mathrm{p}}=\underline{\mathrm{ns}}$, two-tailed). The same pattern was also apparent for the crime theft from vehicle (odds ratio $=0.93, \underline{z}=0.55, \underline{p}=\underline{n s}$, two-tailed). Thus, whilst it would appear that the operation had a significant effect on these types of crime during implementation, after the scheme finished the level of crime returned to its pre-operation level.

Considering the distance over which the scheme had an impact, for the crimes for which there was evidence of a reduction within the $200 \mathrm{~m}$ buffer zone, we computed odds ratios for the adjacent buffer zones. As noted above, the additional 200m buffer zones overlapped each other. The reason for adopting this approach was to increase the sensitivity of the analyses, whilst using buffer zones that were sufficiently large enough to minimise the likelihood of type I statistical error.

Thus, we computed odds-ratios for buffer zones that extended 0-200m, 100-300m, 200-400m, 300-500m from the bus route. The results for the crime assault are shown in Figure 4. For this crime, the pattern of results apparent for the first three buffer zones suggest that the crime reductive effects of the scheme extended up to $400 \mathrm{~m}$ from the bus 
route. Within the $300-500 \mathrm{~m}$ buffer zone, the reduction observed was not statistically reliable, and hence it is likely that the effect of the scheme did not extend beyond this distance. A similar pattern of results were apparent for theft from vehicle. For comparison purposes, odds ratios were also calculated for the other types of crime for each of the buffer zones. The results showed no systematic patterns, demonstrating that the results observed for assault and theft from car were unique and therefore likely to be attributable to the scheme.

Take in Figure 4 Please

\section{DISCUSSION AND CONCLUSIONS}

In this paper we have used a range of data sets and analytical techniques to examine the effectiveness of a public transport initiative in reducing crime. The operation used a multi-agency partnership that policed a relatively high crime bus route intensively for a period of four weeks. Intended as a pilot scheme, the operation incorporated a number of initiatives including the use of a multi-agency Safer Transport Team and the use of state of the art CCTV equipment. The research has raised a number of conceptual issues as well as testing a series of hypotheses, which will now be discussed in turn.

During the operation a total of 90 arrests were made during the four-week period of operation. For the officers who worked on Bream, their arrest rate increased by a factor of 3-5 times relative to their past performance. It is suggested that the increase in arrest rates was one of the most significant factors in the success of Operation Bream. Considering the theoretical mechanisms of change discussed in relation to the operation in the introduction, 
this finding also provides evidence to support claims that there was a causal link between the interventions and the reduction in levels of crime and disorder observed along the bus route. Specifically, this finding suggests that by increasing officer arrest rates as well as the visibility of policing along the route, the operation had a deterrent effect.

Considering the changes in crime and disorder in more detail, it was apparent that the demand for police service, as measured by changes in the number of calls to the police and specifically for calls relating to disorder only, decreased during the operation. Similarly, reductions were apparent for most types of crime, although these changes were only statistically reliable for two types of crime, assault and theft from car. Where there was evidence of an increase in a particular type of crime this was minor and statistically unreliable, thereby demonstrating that the initiative did not cause crime switch displacement. Finally, with the exception of the number of calls for police service, levels of crime and disorder returned to their pre-operation levels following the termination of the scheme, indicating that the scheme did not have a residual deterrence effect.

In relation to geographical displacement, unlike most crime prevention initiatives there was no clearly delineated operational boundary for the scheme, as police officers could have patrolled a number of areas around the bus route, and the geographical coverage of the other interventions may have extended beyond the immediate boundary of the route. Data regarding these factors were unavailable here, and hence the possibility exists that any changes observed for areas near to, but not along the bus route, may have occurred as a direct result of the scheme, rather than as a side effect. As a result, rather than conceptualising changes around the route specifically in terms of displacement or diffusion of benefit, we elected to examine the distance over which the scheme could plausibly have had an impact, be it positive or negative. It was evident that for assault and theft from car, 
the two crimes for which there was evidence of a reliable reduction along the bus route, statistically reliable reductions were apparent across a series of buffer zones that extended up to $400 \mathrm{~m}$ from the bus route. In the subsequent buffer zone, the change observed was not reliable in statistical terms. Thus, it is likely that the scheme was successful at reducing some types of crime up to $400 \mathrm{~m}$ from the bus route. The question of whether the reductions observed beyond the immediate buffer zone $(200 \mathrm{~m})$ of the bus route were a direct result of the scheme or at least partly attributable to a diffusion of benefit remains an interesting question that may be addressed by future research. To do this, it would be necessary to collect data on police officer patrolling patterns and the precise range over which each of the interventions could plausibly have an impact.

Taken together, the above findings suggest that the operation was effective in reducing crime and disorder along the action route. Further to this, anecdotal evidence generated from informal questionnaires of both the public and staff involved in the operation suggested that the operation was well received. Hence, a further avenue for future research would be to explore staff and passenger perceptions of the operation in more detail and to examine the effect of similar operations on people's fear of crime using before and after surveys.

The authors suggest that similar multi-agency police operations could be undertaken elsewhere with positive results. On Merseyside for example, although the action route experienced relatively high levels of bus recorded crime, 19 routes with higher levels of crime could be identified from MASS security records. As noted above, problems exist in identifying the nature and extent of crime on buses, and hence it is recommended that thought should be given to the recording systems used to capture information concerning crime and disorder on buses. This would allow a more precise matching of the problems 
faced on different bus routes and the interventions that might be implemented to ameliorate them. Clearly, future research should also aim to explore whether interventions aimed at reducing crime and disorder on public transport are more effective in different types of area and environments, and, if so, what the composition of such areas are.

The results in figure 3 suggest that, in general, the operation had a greater impact on personal and violent crimes as opposed to traditional property crime (although only a minority of the reductions were significant). Thus, the authors recommend that in future different variants of the initiative should be implemented to see if they have differential effects on crime and types of crime. For instance the use of plain clothed rather than uniformed officers might lead to an increase in arrests for different types of crime. For this reason, during the planning phase of future initiatives, thought should be given to the types of crime to be targeted for reduction and the theoretical rationale underlying the approach(es) considered.

Where similar operations are implemented in the future, thought also should be given to the timing of implementation. To increase the impact of the scheme, seasonal trends in patterns of crime and disorder should be considered to ensure that routes with appropriately high rates of crime are targeted at the right times. The time of day that particular interventions are implemented may also be important. In the current research, for example, there was some evidence that more arrests were made during the late afternoon and evening police shifts. There was also evidence that the initiative was more successful during the first two weeks of implementation. Thus, it may be wise to implement similar initiatives as short-run intensive operations (possibly 7-14 days at a time), and alternate implementation across a series of different bus routes. Disinformation and publicity 
strategies may also be used to enhance the effectiveness of schemes where such an approach is adopted (see Smith et al., 2002; Johnson and Bowers, 2003).

The current research demonstrates a number of methods that can be used in the evaluation of crime prevention measures aimed at reducing crime on public transport routes. The results suggest that the scheme was successful in increasing officer arrest rates and reducing crime and disorder along the action route. An important concept discussed above relates to the area over which such operations are likely to have an impact, and how there effectiveness may consequently be measured. In the analyses presented, as a starting point we defined the action area as a $200 \mathrm{~m}$ buffer zone that surrounded the bus route. However, it is reasonable to suggest that the area over which the scheme may have an effect could vary at different points along the route. Reasons for suggesting this include the influence of factors that may affect police officer's visibility, in terms of how far from the vehicle they can see at different points along the route, or alternatively how far police officers patrol either side of the bus route. Thus, where differences exist, how does one distinguish between changes that occur as a side effect of the scheme (displacement or a diffusion of benefit) or that are directly attributable to the scheme itself?

In this paper, we have presented a number of suggestions for future research, but particularly important questions concern when and where such schemes are successful and whether they impact upon passengers (and employees) fear of crime as well as levels of crime and disorder. In addition to examining the effectiveness of such schemes on levels of crime and disorder, future research may also consider the process through which the interventions are delivered and how cost beneficial these types of intervention are. 


\section{$\underline{\text { ACKNOWLEDGEMENTS }}$}

The authors would like to express thanks to Merseyside Police and in particular Inspector Kevin Rigby for his advice and guidance during the course of this research. Operation Bream was funded to a large extent by the Home Office Reassurance Fund. 


\section{REFERENCES}

Anderson, D. Chenery, S. and Pease, K. (1995) Biting Back: Tackling Repeat Burglary and Car Crime. Home Office Crime Detection and Prevention Series, Paper 58. London. Home Office.

Atkins, S. (1990) Personal Security as a Transport Issue: a state of the art review. Transport Reviews. 10 (2) 111-125

Baker, J. and Bewick, I. (2001) Personal Security on Public Transport. Cambridge. Transport and Travel Research (TTR)

Bowers, K and Hirschfield, A. (1999) Exploring links between crime and disadvantage in North-West England: an analysis using geographical information systems. International Journal of Geographical Information Science. 13 (2) 159-184.

Bowers, K.J. \& Johnson, S.D. (2003) Measuring the Geographical Displacement of Crime. Journal of Quantitative Criminology. 19 (3) 275-301.

Bowers, K.J., Johnson, S.D., \& Hirschfield, A.F.G. (2003). Pushing Back the Boundaries: New Techniques for Assessing the Impact of Burglary Schemes. Home Office Online report 24/03. Home Office: London.

Carr, K. and Spring, G. (1993). Public Transport Safety: A community right and a communal responsibility, in Clarke, R. (ed). Crime Prevention Studies Volume 1. Monsey, NY: Criminal Justice Press. 147-155.

Cohen, L. and Felson, M. (1979) Social Change and Crime Rate Trends: A Routine Activity Approach. American Sociological Review. 44. 588-608.

Department for Transport, Local Government and the Regions (DTLR) (2002). Get on Board: an agenda for improving personal security in bus travel. London. DTLR

Department of the Environment, Transport and the Regions (DETR). (1998). A New Deal for Transport: Better for Everyone. London. DETR.

Department of the Environment, Transport and the Regions (DETR) (1999). Personal Security Issues in Pedestrian Journeys. London. DETR

Easteal, P. and Wilson P, R. (1991) Preventing Crime on Transport. Canberra. Australian Institute of Criminology (AIC).

Eck, J. (1997) Preventing Crime at Places, in Sherman, L., Gottfredson, D., MacKenzie, D., Eck, J., Reuter,P. and Bushway, S. (eds) Preventing Crime: What Works, What Doesn't, What's Promising. Washington DC. National Institute of Justice (NIJ) 
Farrington, D. and Welsh, B. (2002) Effects of improved street lighting on crime: a systematic review. Home Office Research Study 251. London. Home Office.

Felson, M., Belanger, M., and Bichler,G. (1996) Redesigning Hell: Preventing crime and disorder at the port authority bus terminal, in Clarke, R. Preventing Mass Transit Crime. Crime Prevention Studies Volume 6. Monsey, NY. Willow Tree Press. 5-93.

Hamilton-Smith, N. (2002). Anticipated consequences: Developing a strategy for the targeted measurement of displacement and diffusion of benefit, in Tilley, N. (ed). Crime Prevention Studies Volume 14. Monsey, NY: Criminal Justice Press. 11-52.

Johnson, S. and Bowers, K. (2003) Opportunity is in the eye of the beholder: The role of publicity in crime prevention. Criminology and Criminal Policy 2 (3) 201-228.

Johnson, S.D., Bowers, K.J., Young, C.A., \& Hirschfield, A.F.G. (2001) Uncovering the True Picture. Evaluating Crime Reduction Initiatives using Disaggregate Crime Data. Crime Prevention and Community Safety: An International Journal. 3 (4). 7-24.

LaVigne, N. (1997) Visibility and Vigilance: Metro's situational approach to preventing subway crime. Washington, DC. National Institute of Justice.

Laycock G. and Webb, B. (1992) Reducing Crime On the London Underground. An evaluation of three pilot projects. Crime Prevention Unit Paper 30. London. Home Office

Levine, N., Wachs, W., and Shirazi, E. (1986) Crime at Bus Stops. A study of environmental factors. Journal of Architectural and Planning Research, 3(4). 339-361.

Lipsey, M. and Wilson, D. (2001) Practical meta-analysis. Thousand Oaks, CA. Sage Publications.

Miethe, T. D. (1991) Citizen-based Crime Control Activity and Victimisation Risks: an Examination of Displacement and Free-Rider Effects. Criminology. 29(3) 419-439.

Mirlees-Black, C., Budd, T., Partridge, S. and P. Mayhew (1998) The 1998 British Crime Survey. London. Home Office.

Needle, J, and Cobb, R. (1997) Improving Transit Security. A Synthesis of Transport Practice. TCRP Synthesis 21.Washington DC. Transportation Research Board

Nelson, K. (1997). Policing Mass Transit: Serving a Unique Community. Federal Bureau of Investigation Law Enforcement Bulletin. January 1997. Washington DC US Department of Justice.

Poyner, B. (1993) Design Against Crime. Beyond Defensible Space. London. Butterworths. 
Sherman. L. (1990) Police Crackdowns: Initial and residual deterrence. In Tonry, M. and Morris, N. (eds) Crime and Justice: A Review of Research Volume 12. Chicago. The University of Chicago Press. 1-48

Sherman, L., Gottfredson, D., MacKenzie, D., Eck, J., Reuter,P. and Bushway, S. (eds). (1998) Preventing Crime: What Works, What Doesn't, What's Promising. Washington DC. National Institute of Justice (NIJ)

Smith, M. and Clarke, R. (2000) Crime and Public Transport, in Clarke, R. (ed) Crime and Justice. A Review of Research Volume 27. Chicago. The University of Chicago Press. 169234.

Smith, M. Clarke, R. and Pease, K. (2002) Anticipatory benefits in crime prevention, in Tilley, N. (ed) Crime Prevention Studies Volume 13. Monsey, NY: Criminal Justice Press. 71-88.

Van Andel, H. (1989) Crime Prevention That Works: The care of public transport in the Netherlands. British Journal of Criminology. 29 (1) 47-56.

Visher, C. and Weisburd, D. (1998) Identifying What Works: Recent Trends in Crime Prevention Strategies. Crime, Law \& Social Change 28: 223-242.

Weiss, C. (1998) Evaluation: Methods for Studying Programs and Policies. New Jersey. Prentice Hall 
Table I Average Arrest Rates for Operation Bream and a Comparison Period

\begin{tabular}{|c|c|c|}
\hline & $\begin{array}{l}\text { Average daily arrest } \\
\text { Rate (Bream) }\end{array}$ & $\begin{array}{l}\text { Average daily arrest } \\
\text { Rate (Merseyside) }\end{array}$ \\
\hline Baseline (low to high) & range 0.09 to 0.15 & range 0.05 to 0.10 \\
\hline Operation Bream & 0.41 & range 0.06 to 0.10 \\
\hline
\end{tabular}


Figure 1 Location of Action Route and 100m Concentric Buffer Zones

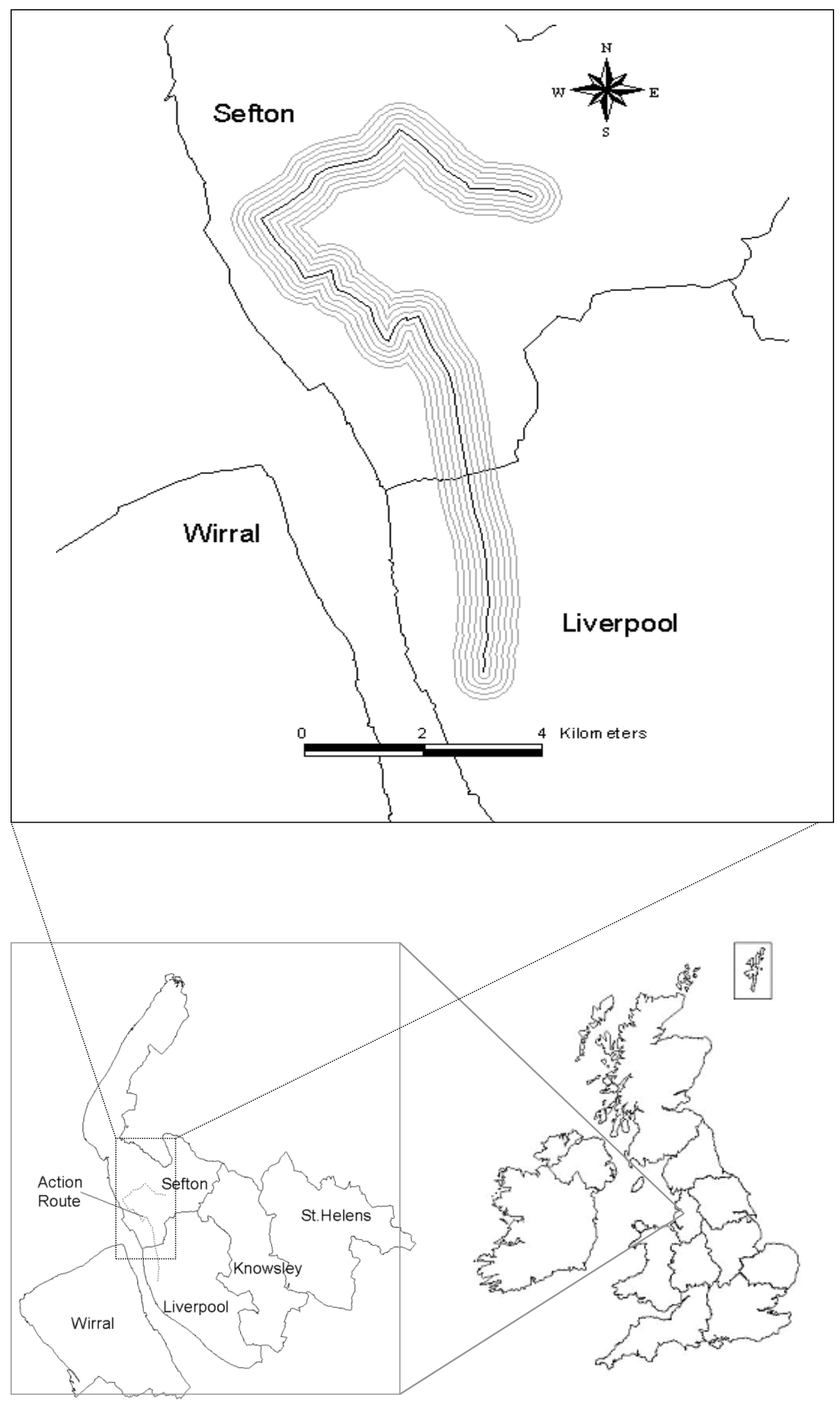


Figure 2 Calls for Service per 1000 Households for Action Route and Reference Area

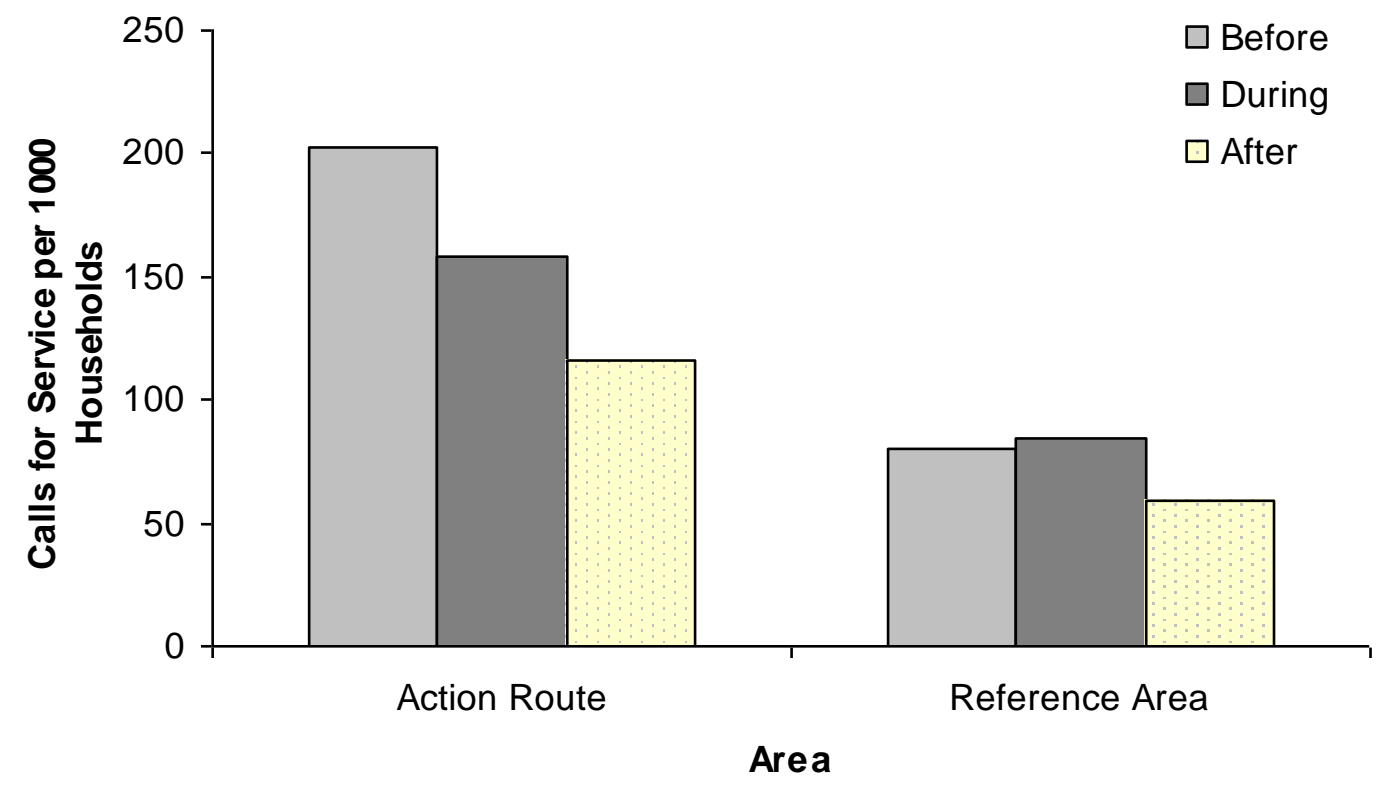


Figure 3 Odds ratios for the $(200 \mathrm{~m})$ action area using the remainder of Merseyside as the reference area

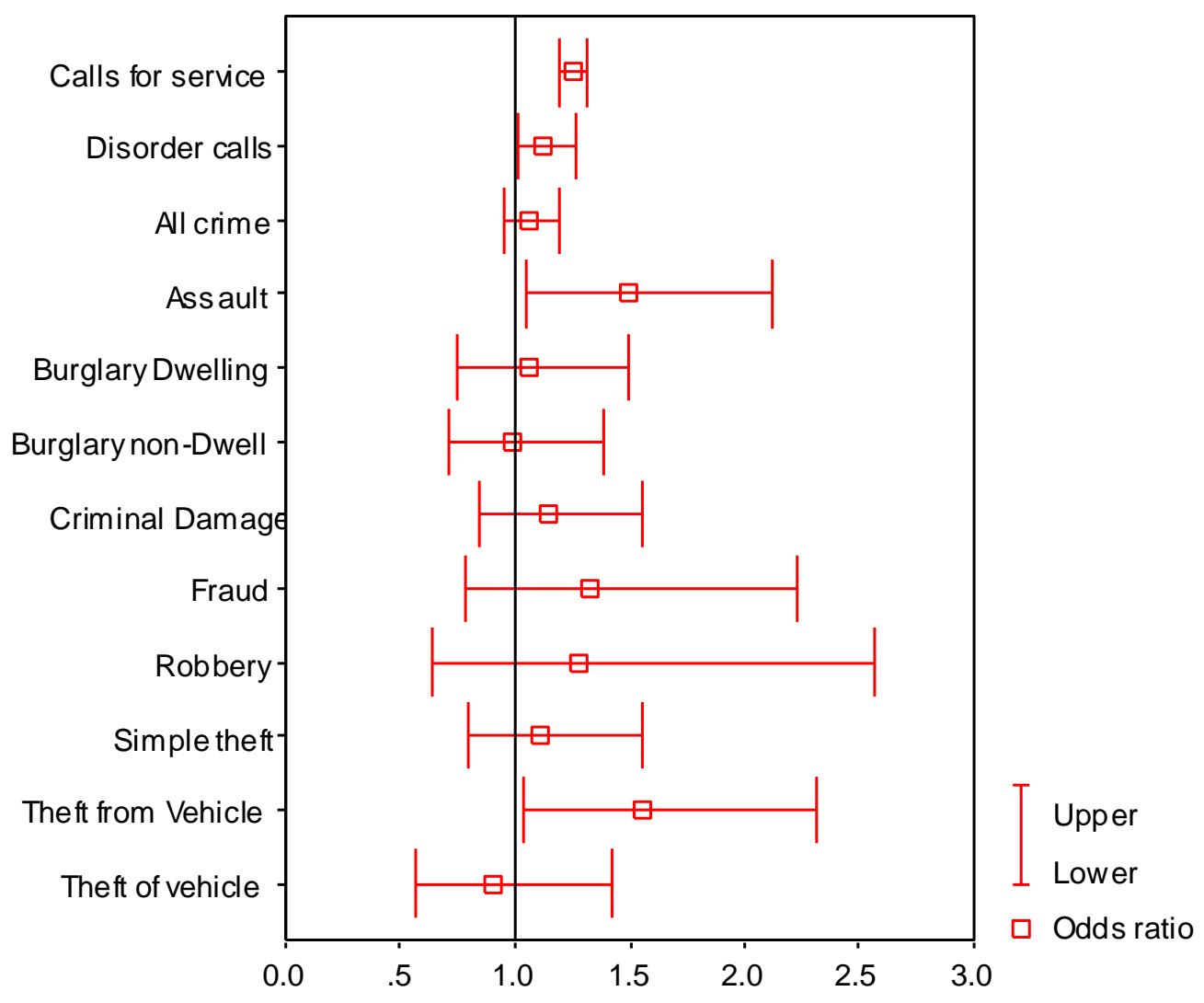


Figure 4 Odds Ratio for assault for a series of buffer zones, using the rest of Merseyside as a reference area.

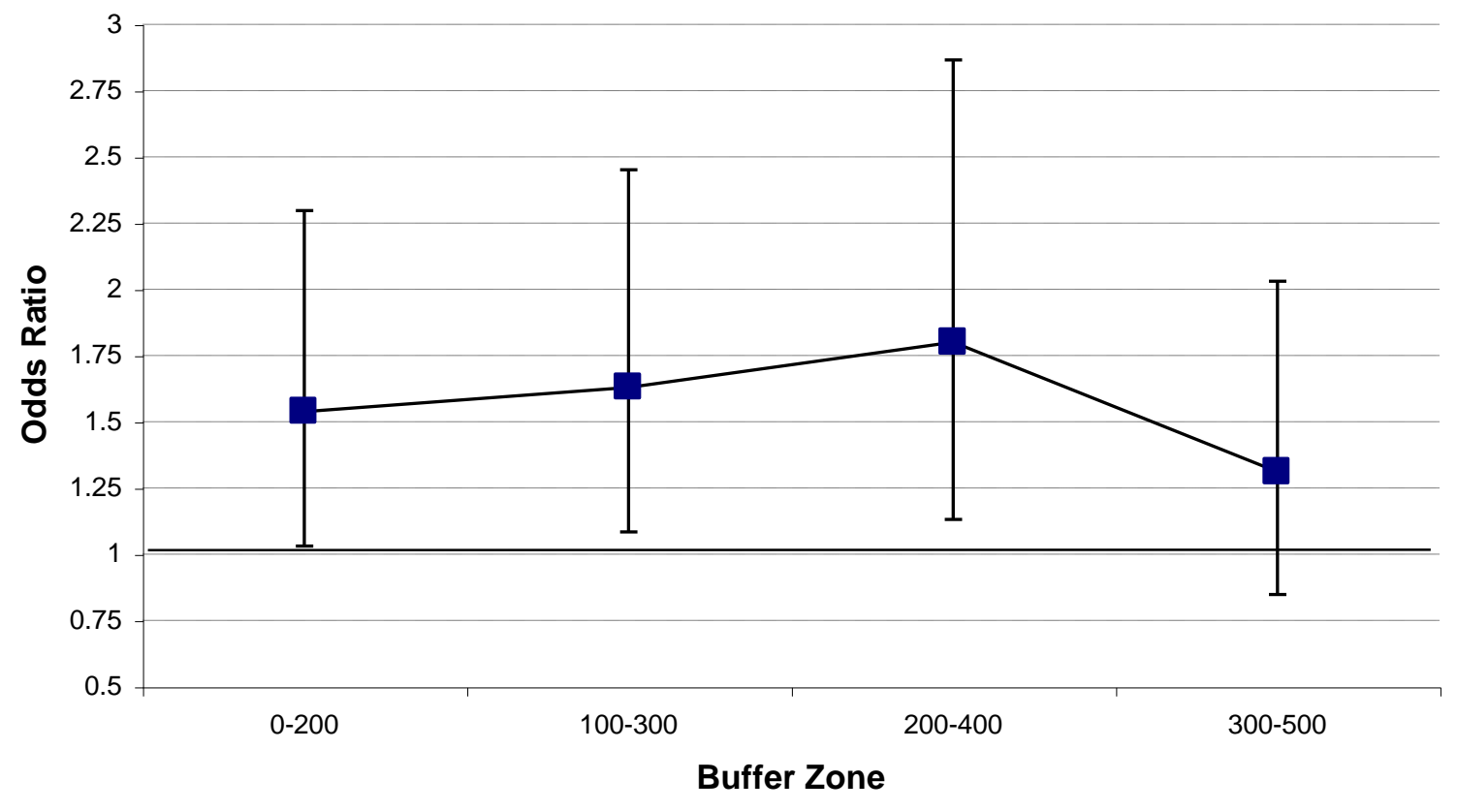

